\title{
The Spatial Dimensions of Electrically Coupled Networks of Interneurons in the Neocortex
}

\author{
Yael Amitai, ${ }^{1,2}$ Jay R. Gibson, ${ }^{1}$ Michael Beierlein, ${ }^{1}$ Saundra L. Patrick, ${ }^{1}$ Alice M. Ho, ${ }^{1}$ Barry W. Connors, ${ }^{1}$ \\ and David Golomb² \\ ${ }^{1}$ Department of Neuroscience, Brown University, Providence, Rhode Island 02912, and 2Department of Physiology and \\ Zlotowski Center for Neuroscience, Faculty of Health Sciences, Ben-Gurion University, Beer-Sheva 84105, Israel
}

Inhibitory interneurons of the neocortex are electrically coupled to cells of the same type through gap junctions. We studied the spatial organization of two types of interneurons in the rat somatosensory cortex: fast-spiking (FS) parvalbumin-immunoreactive $(\mathrm{PV}+)$ cells, and low threshold-spiking (LTS) somatostatinimmunoreactive (SS+) cells. Paired recordings in layer 4 demonstrated that both the probability of coupling and the coupling coefficient drop steeply with intersomatic distance, reaching zero beyond $200 \mu \mathrm{m}$. The dendritic arbors of FS and LTS cells were reconstructed from electrophysiologically characterized, biocytinfilled cells; the two cell types had only minor differences in the number and span of their dendrites. However, there was a markedly higher density of PV + cells than SS + cells. PV + cells were densest in layer 4, while SS + cell density peaked in the subgranular layers. From these data we estimate that there is measurable electrical coupling (directly or indirectly via intermediary cells) between each interneuron and 20-50 others. The large number of electrical synapses implies that each interneuron participates in a large, continuous syncytium. To evaluate the functional significance of these findings, we examined several simple architectures of coupled networks analytically. We present a mathematical method to estimate the average summated coupling conductance that each cell receives from all of its neighbors, and the average leak conductance of individual cells, and we suggest that these have the same order of magnitude. These quantitative results have important implications for the effects of electrical coupling on the dynamic behavior of interneuron networks.

Key words: FS cells; LTS cells; inhibitory interneurons; gap junctions; dendritic fields; coupling coefficient; coupling conductance; network architecture
The circuitry of the neocortex has traditionally been represented by maps of neurons that are interconnected by axons and chemical synapses (Braitenberg, 1978; White, 1989). This is an impoverished view, however, because there is now strong evidence that electrical synapses are also a frequent and important feature of neocortical circuits. Electrical synapses are most prevalent between inhibitory interneurons (Galarreta and Hestrin, 1999; Gibson et al., 1999). The circuits defined by electrical synapses can be highly specific; among two common types of interneurons in the neocortex, the large majority of electrical synapses interconnect cells of the same type (Gibson et al., 1999). The importance of electrical synapses to the function of the neocortex is still poorly understood, but recent studies suggest a role in neuronal synchronization and rhythm generation (Benardo, 1997; Beierlein et al., 2000; Galaretta and Hestrin, 2001; Deans et al., 2001).

Understanding what electrical synapses do in the neocortex, and precisely how they do it, will require quantitative information about the patterns of neural circuits defined by electrical connections. Important issues include the incidence of connectivity, the organization and the size of coupled assemblies of neurons, and the strength of the electrical coupling each cell has with other cells. These kinds of data have been hard to come by. The

Received Dec. 4, 2001; revised Feb. 1, 2002; accepted Feb. 15, 2002.

This research was supported by National Institutes of Health Grants NS25983 and DA125000 (B.W.C.), United States-Israel Binational Science Foundation Grants 9700043 (Y.A., B.W.C.) and 9800015 (D.G.), and Israel Science Foundation Grant 59/98 (Y.A.). We thank E. Bienenstock, D. Hansel, and C. Meunier for helpful discussions.

Correspondence should be addressed to Dr. Yael Amitai, Department of Physiology, Faculty of Health Sciences, Box 653, Ben-Gurion University, Beer-Sheva 84105, Israel. E-mail: yaela@bgumail.bgu.ac.il.

Copyright (C) 2002 Society for Neuroscience $0270-6474 / 02 / 224142-11 \$ 15.00 / 0$ anatomical basis of electrical synapses is the gap junction (Bennett, 1977), a structure visible only with electron microscopy. Very few studies have described gap junctions between neurons in the mammalian forebrain, and most of these have been between certain types of interneurons in either the neocortex (Sloper, 1972) or hippocampus (Kosaka, 1983; Kosaka and Hama, 1985). Unlike chemical synapses in the cerebral cortex, gap junctions have been seen most frequently at dendrodendritic and dendrosomatic sites (Sloper and Powell, 1978; Tamás et al., 2000; Szabadics et al., 2001). Although this is very important information, it does not reveal the scale of electrical coupling at the level of larger interneuronal circuits.

We have used data derived from dual recordings of electrically coupled neurons in the rat somatosensory cortex, anatomical reconstructions and immunohistochemistry for specific markers of GABAergic neurons, and theoretical analysis to study the spatial distribution of two coupled populations of interneurons in the neocortex. Our goal has been to provide quantitative answers to the following questions: Do coupled neurons form small, restricted clusters or large, continuous networks? On average, how many neurons are coupled to each individual neuron? What are the effects of gap junctions on the biophysical properties of the neurons and the network? Our data suggest that GABAergic neurons of the neocortex form large electrically interconnected networks, where each neuron contacts tens of other neurons. We also show that the input conductance attributable to nonjunctional membrane and that attributable to the sum of electrical synapses onto all other neurons have similar magnitudes; this implies that approximately one-half of the input conductance measured experimentally is contributed by gap junctions. 


\section{MATERIALS AND METHODS}

Slice preparation and recording. Thalamocortical slices $400 \mu \mathrm{m}$ thick were obtained from Sprague-Dawley rats aged postnatal day 14 (P14) to P21, as described previously (Gibson et al., 1999). The slices were incubated for 1 hour and then placed in a submersion chamber at $32^{\circ} \mathrm{C}$ for recording. The bathing solution contained (in $\mathrm{mm}$ ): $126 \mathrm{NaCl}, 3 \mathrm{KCl}, 1.25$ $\mathrm{NaH}_{2} \mathrm{PO}_{4}, 2 \mathrm{MgSO}_{4}, 26 \mathrm{NaHCO}_{3}, 10$ dextrose, and $2 \mathrm{CaCl}_{2}$, saturated with $95 \% \mathrm{O}_{2} / 5 \% \mathrm{CO}_{2}$. Micropipettes were filled with (in $\mathrm{mM}$ ): 135 K-gluconate, $4 \mathrm{KCl}, 2 \mathrm{NaCl}, 10 \mathrm{HEPES}, 0.2-4$ EGTA, 4 ATP-Mg, 0.3 and GTP-Tris, 0.5-10 phosphocreatine-Tris, $\mathrm{pH} 7.25,295$ mOsm. In some experiments, neurobiotin or biocytin $(4 \mathrm{mg} / \mathrm{ml})$ was added to the normal filling solution. All recordings were made in current-clamp mode, under infrared-differential interference contrast visualization. All neurons were classified according to their firing pattern in response to an injection of a square current pulse as either fast spiking (FS) cells or low-threshold spiking (LTS) cells (details given in Gibson et al., 1999). When depolarized, FS cells fired with high frequencies of narrow action potentials, with little or no frequency adaptation. LTS cells had a tendency to fire on the rebound when depolarized from more negative membrane potentials, their spikes were broader, and they exhibited clear frequency adaptation. To characterize the electrical coupling between two cells, a step current was injected into one cell and the voltage responses of both cells were measured (see also Gibson et al., 1999). The coupling coefficient (CC) was defined as the ratio between the steadystate voltage deflection of the postjunctional cell and that of the prejunctional cell. Cells are defined as "electrically coupled" if the measured CC between them is $>0.01$, the smallest that can be reliably distinguished above the membrane voltage noise.

Histological procedures. Slices that contained stained cells were fixed in $4 \%$ paraformaldehyde in $0.1 \mathrm{M}$ phosphate buffer, transferred to $30 \%$ sucrose, resectioned to $80 \mu \mathrm{m}$, and reacted with the avidin-biotinperoxidase [avidin-biotin complex $(\mathrm{ABC})$ ] procedure (Vector Laboratories, Burlingame, CA). For immunohistochemistry, Sprague-Dawley rats aged P16-P18 were anesthetized with $30 \mathrm{mg} / \mathrm{kg}$ pentobarbital, perfused intracardially with $5 \mathrm{ml}$ of heparinized saline followed by $4 \%$ paraformaldehyde in $0.1 \mathrm{M}$ phosphate buffer, $\mathrm{pH}$ 5.4, for $25 \mathrm{~min}$. Brains were removed, hemisected, and placed in fixative for an additional $2 \mathrm{hr}$ before changing to $0.1 \mathrm{M}$ phosphate buffer. Subsequently, tissue was cryoprotected in 30\% sucrose/0.1 M phosphate buffer, $\mathrm{pH} 7.4$, overnight. The tissue was sliced at $60 \mu \mathrm{m}$ along the thalamocortical plane (Agmon and Connors, 1991), which is approximately parallel to the barrel rows. Tissue was washed three times in PBS $(0.1 \mathrm{M}$ phosphate $/ 0.15 \mathrm{M} \mathrm{NaCl}$ at $\mathrm{pH}$ 7.4) before incubation in $0.5 \% \mathrm{H}_{2} \mathrm{O}_{2}$ for $1 \mathrm{hr}$. Slices were washed three times in PBS followed by three more washes in Tris-buffered saline (TBS; $0.05 \mathrm{M}$ Tris/0.15 NaCl, pH 7.4) for $10 \mathrm{~min}$ each. The slices were incubated overnight at room temperature with shaking in primary antiserum for either somatostatin (SS; Peninsula, San Carlos, CA) or parvalbumin (PV; Sigma, St. Louis, MO). Final concentrations of each antiserum were $1: 1000$ and $1: 400$, respectively, including $10 \%$ normal goat serum, $2 \%$ bovine serum albumin, $0.5 \%$ Triton X-100, and TBS (all purchased from Sigma). On day 2, the tissue was washed three times in TBS and incubated $3 \mathrm{hr}$ at room temperature in biotinylated anti-rabbit IgG (Vector Laboratories) using a 1:200 final dilution including 10\% normal goat serum, $2 \%$ bovine serum albumin, $0.5 \%$ Triton $\mathrm{X}-100$, and TBS. After several rinses, an ABC Elite kit (Vector Laboratories) was used to visualize somatostatin or parvalbumin.

Morphometric analysis. Stained cells were digitally reconstructed at $40 \times$ magnification with a Neurolucida system (MicroBrightField Inc., Colchester, VT), and the dendritic branching patterns were evaluated using a standard Sholl analysis (Sholl, 1956). Sections reacted for PV or SS were viewed under the light microscope at $10 \times$ magnification and mapped with Neurolucida software in seven different, randomly selected sections taken from three different animals. Stained cells were counted in at least 2-mm-wide vertical strips across all layers of the primary somatosensory cortex. Background staining was sufficient to allow determination of the borders of cortical laminas. In some cases, adjacent sections were stained for cytochrome oxydase to reveal layer 4 and the barrel structures.

Cell density in thin sections was calculated with the Neurolucida software. For additional analysis, the coordinates of cells in mapped sections were converted into ASCII files and analyzed using a routine written in Matlab. In this routine, cell density was calculated by dividing each section into $30 \times 50 \mu \mathrm{m}$ rectangular bins, and a sliding average of the number of cells was performed in $4 \times 4$ such rectangles. To calculate the volume density of the cells, we made the following measurements and

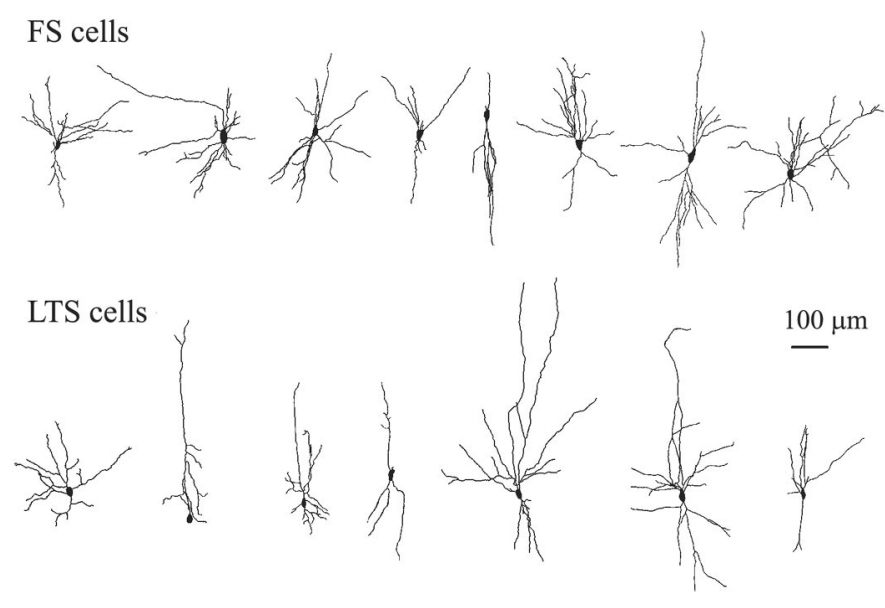

Figure 1. The soma-dendritic morphology of FS and LTS cells is rather variable.

assumptions: (1) The maximal depth of focus (z-axis) was measured with Neurolucida and found to be $\sim 12 \mu \mathrm{m}$. (2) The collapse of the tissue along the $z$-axis was estimated to be $\sim 60 \%$ (Benes and Lang, 2001); thus $12 \mu \mathrm{m}$ represents $30 \mu \mathrm{m}$ of unfixed tissue thickness. (3) Because the somata of many viewed cells in the thin plane of view are cut in the middle, we added another $5 \mu \mathrm{m}$ for each side of the section. Accordingly, the tissue thickness ( $z$-axis) was additionally corrected to a value of 40 $\mu \mathrm{m}$ for calculations of cell density by volume. We call this corrected measure the "effective thickness" of the tissue.

\section{RESULTS}

\section{Morphology of dendritic trees of FS and LTS interneurons}

Ultrastructural studies suggest that gap junctions form between dendrites, or between dendrites and somata, of inhibitory neurons (Tamás et al., 2000; Szabadics et al., 2001). Thus, the potential for such a junction exists wherever dendrosomatic membranes of two cells are in close proximity. We analyzed the spatial extent of the dendritic trees of FS and LTS interneurons. The dendrites of eight FS cells and seven LTS cells that were well stained with biocytin were fully reconstructed (Fig. 1). The dendritic trees of both types had variable profiles, and there was no clear correlation between the physiological type and any common morphological classification of dendritic pattern such as "bitufted" or "multipolar." Other studies of neocortical interneurons have also concluded that the somatodendritic morphology of these cells does not distinguish their subtype (Kawaguchi and Kubota, 1997; Bayraktar et al., 2000). Sholl analysis of the dendrites revealed some quantitative differences between the two cell types (Fig. $2 A, B)$. The total proximal dendritic length $(<200 \mu \mathrm{m}$ from the soma) was $\sim 17 \%$ larger for FS cells than for LTS cells (1690 \pm $640 \mu \mathrm{m}$ and $1440 \pm 890 \mu \mathrm{m}$, respectively), because FS cells had more primary dendrites and proximal branching (Fig. 1). However, the dendrites of FS cells rarely extended beyond $400 \mu \mathrm{m}$, whereas some LTS cells possessed branches that extended $>600$ $\mu \mathrm{m}$. These longer dendrites were usually vertically oriented, ascended toward the pia, and account for the long tail in the LTS Sholl histogram (Figs. 1, 2B) and the small deviation to the right in the cumulative probability plot (Fig. $2 C$ ). For both cell types, $\sim 80-90 \%$ of their total dendritic length occurred within $200 \mu \mathrm{m}$ from the soma (Fig. $2 C$ ). We conclude that the dendritic profiles of FS and LTS cells in layer 4 are similar in their general outline, and show only minor quantitative differences. 


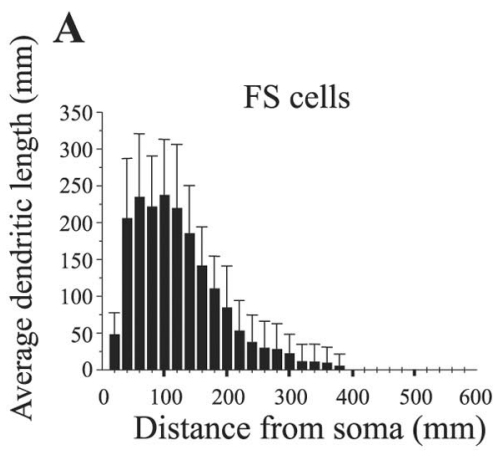

B

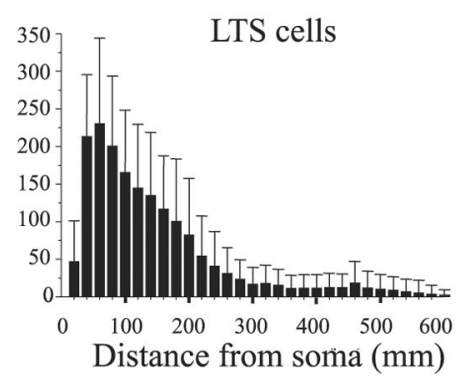

C

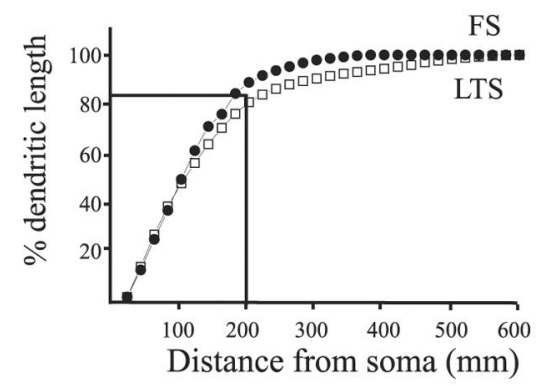

Figure 2. Sholl analysis of the inhibitory neurons from Figure 1 reveals more primary branches for FS cells $(A)$ and a "tail" of longer branches in LTS cells $(B)$. Comparing the cumulative length of the two cell types shows that for both, $80-90 \%$ of the dendrites occurred within $200 \mu \mathrm{m}$ of the soma. FS cells, closed circles; LTS cells, open squares.
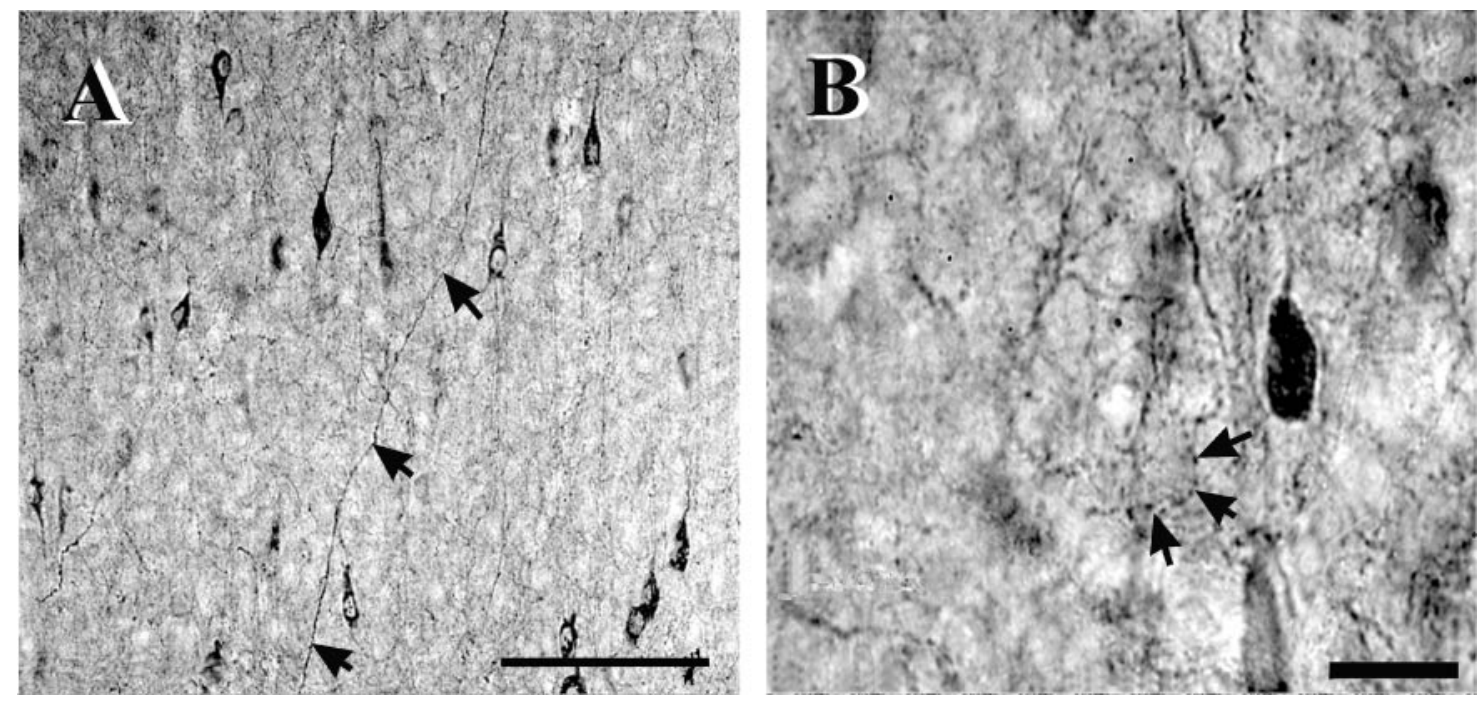

Figure 3. Immunohistochemistry for somatostatin $(A)$ and parvalbumin $(B)$ in layer 4. Arrows in $A$ point to a somatostatin-positive axon crossing upward. Arrows in $B$ point to punctate parvalbumin-positive terminal staining around the somata of cells. Scale bars: $A, 100 \mu \mathrm{m} ; B, 20 \mu \mathrm{m}$.

\section{The spatial distribution of parvalbumin- and somatostatin-immunoreactive cells}

Previous studies from our laboratory showed that FS cells were generally parvalbumin immunoreactive $(\mathrm{PV}+)$, while most LTS cells were somatostatin immunoreactive (SS+) (Gibson et al., 1999). Studies from other laboratories have also concluded that $\mathrm{PV}+$ and SS + cells correspond to two such specific and nonoverlapping populations of interneurons, distinguished by morphology and electrophysiology (Kubota et al., 1994; Gonchar and Burkhalter, 1997; Kawaguchi and Kubota, 1997). We used these molecular markers to analyze the spatial organization of the two classes of interneuron populations quantitatively. Sections of barrel cortex were cut in either the thalamocortical plane angle as used for our electrophysiology experiments (Agmon and Connors, 1991) or in the tangential plane parallel to the pia and then processed for PV or SS immunoreactivity. Both immunostaining methods stained only partial dendritic arbors. There were, however, striking differences in the patterns of axonal immunostaining. Single SS + axons were seen coursing for hundreds of microns through single sections, most often along the vertical dimension (Fig. 3A). There was an especially dense plexus of $\mathrm{SS}+$ axons in layer 1 . These features are consistent with the axonal arborization features of Martinotti cells, which have vertically projecting axons that arborize in layer 1, and which are SS+ (Kawaguchi and Kubota, 1997). In contrast, PV+ axons could rarely be traced for any significant length. Instead, PV sections had numerous clear rings of stained boutons surrounding the somata of unstained cells. These were especially prominent in layer 4 (Fig. 3B), and are consistent with the general conclusion that many PV+ cells are basket cells (Hendry et al., 1989; Akil and Lewis, 1992).

The average density of PV + cells across the entire cortical thickness was larger than that of SS + cells $(92 \pm 9$ vs $67 \pm 12$ cells $/ \mathrm{mm}^{2}$, respectively). Because our estimated effective thickness of the sections is $40 \mu \mathrm{m}$ (see Materials and Methods), we calculated that the average neuron density by volume $(\rho)$ was $\sim 2300 \pm 225$ cells $/ \mathrm{mm}^{3}$ for PV + cells and $1675 \pm 300$ cells $/ \mathrm{mm}^{3}$ for $\mathrm{SS}+$ cells.

Both interneuron types were present in layers 2 through 6 , but they had very different distributions of density. The density of $\mathrm{PV}+$ cells was especially high in layer 4 , whereas SS + cells were more concentrated in lower laminas (Fig. 4). Tangential sections through layer 4 revealed a higher density of $\mathrm{PV}+$ cells inside the barrel borders (data not shown; Sanchez et al., 1992; McMullen et al., 1994). Autocorrelation of the radius vector of each cell against all other cells in tangential sections through several layers did not reveal any anisotropy for both cell types (data not shown). 


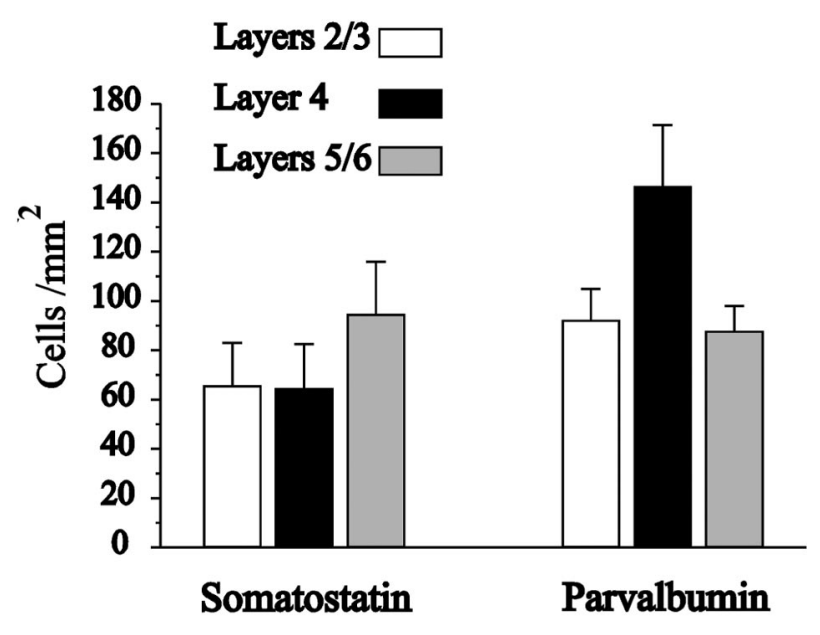

Figure 4. Average density of somatostatin-positive and parvalbuminpositive cells in the different cortical laminas.

The spatial distribution of the two interneuron types was also highlighted by a bin-averaging process (Fig. 5). Each histological section was divided into rectangular bins of $30 \times 50 \mu \mathrm{m}$ (the smaller side parallels the pia), and the smoothing process averaged an area of $4 \times 4$ such bins $(120 \times 200 \mu \mathrm{m})$. This averaging area roughly matches the dimensions of the dendritic fields of the neurons, which show a clear vertical bias (Jin et al., 2001). Sholl analysis demonstrates that such an area encloses $\sim 80 \%$ of the average dendritic tree. Electrophysiological recordings also verified that there was no electrical coupling between cells whose somata were $>200 \mu \mathrm{m}$ apart (see below). Figure 5 displays three representative sections for each immunoreactive cell type. PV+ cells formed a clear band of high-density patches in layer 4 (Fig. $5 A$ ) and another weaker band in layer 6 . The distribution of SS+ cells was more irregular, with high-density patches in the lower laminas (Fig. 5).

Figure 5 also reveals the degree of potential overlap between dendritic fields in these thin sections. One would expect such an overlap if there are at least two cell bodies in a rectangle of $120 \times$ $200 \mu \mathrm{m}$, which corresponds to light blue on the color scale $(0.125$ cells in each single bin of $30 \times 50 \mu \mathrm{m})$. It is apparent from Figure 5 that even in these thin sections, and for the relatively sparse $\mathrm{SS}+$ cell network, there is almost a continuity of overlapping dendritic fields. In a three-dimensional network of cells, such a continuity of dendritic fields is bound to be robust.

\section{Probability of coupling and coupling coefficients}

What determines the likelihood that two interneurons will be coupled? The fact that the dendritic fields of two adjacent neurons overlap does not necessarily mean that their dendrites are in contact or that there are gap junctions interconnecting them. To estimate more directly the relationship between cell proximity and electrical coupling, we performed electrophysiological experiments. Pairs of inhibitory cells were recorded in layer 4 of the barrel cortex. Electrical coupling was common between pairs of interneurons of the same type and rare between pairs of interneurons of different types, as described previously (Gibson et al., 1999; Deans et al., 2001). Of 125 cell pairs consisting of the same types of interneurons, 75 were electrically connected (FS-FS, 52 of 88 pairs, or $59 \%$, were coupled; LTS-LTS, 23 of 37 pairs, or $62 \%$, were coupled). Data for the two types of cells were pooled, because statistical analysis did not reveal any differences.
A critical issue for this study is the distance-dependence of electrical coupling. For each pair of recorded cells, the distance $x$ between the centers of the somata and the angle relative to the vertical orientation of the cortex were measured. If the two cells were electrically connected, we measured the coupling coefficient $(C C)$. The probability $P_{\mathrm{E}}(x)$ that two neurons recorded simultaneously were electrically coupled, and the histogram of $C C(x)$, were deduced from the data (Fig. $6 A, B$ ). Examining the relationship between $P_{\mathrm{E}}(x)$ and $C C(x)$ and the angle between the two coupled cells as defined above did not reveal anisotropy (data not shown). Obviously, the product $P_{\mathrm{E}}(x) \times C C(x)$, which is proportional to the total amount of electrical conductance a cell receives from its coupling to other cells at a distance $x$ from it, decays rapidly with $x$ (Fig. 6C). No coupled pairs were observed at distances of $>200 \mu \mathrm{m}$. We can infer from this, together with the average dendritic spread (Fig. 2C), that most directly coupled pairs of neurons have substantial dendritic overlap.

When electrical coupling is detected between two neurons, it may occur through a direct gap junctional contact or indirectly via intermediary cells that connect the two recorded cells. Without a structural analysis of each cell pair, it is not possible to distinguish direct from indirect coupling. We define $M$ as the average number of cells that are directly connected by gap junctions to each interneuron. We define $M_{\mathrm{E}}$ as the average number of neurons that are electrically coupled to each neuron either by direct contact or indirectly via intermediary neurons. $M_{\mathrm{E}}$ is limited, in practice, to neurons coupled strongly enough (via any route) to be measurable under our recording conditions. The smallest $C C$ we were routinely able to measure with confidence was $\sim 0.01$, because of membrane potential noise (which typically had a SD of $\sim 0.16$ $\mathrm{mV}$ ) and our limited averaging protocol (Gibson et al., 1999). $M_{\mathrm{E}}$ is an upper bound for $M$ (assuming that all the direct electrical connections between cells have $C C$ s that are larger than the confidence limit). We can calculate $M_{\mathrm{E}}$ in a volume of tissue using the following formula:

$$
M_{\mathrm{E}}=4 \pi \rho \int_{0}^{\infty} d x x^{2} P_{\mathrm{E}}(x)
$$

The integral in Equation 1 is approximated by sums over shells, such that in each shell the values of $P_{\mathrm{E}}$ are those in Figure $6 A$. Each shell is $50 \mu \mathrm{m}$ wide; the number of shells $(m)$ is $4, r_{\mathrm{j}}=j \times$ $50 \mu \mathrm{m}$ and $r_{0}=0$ :

$$
M_{\mathrm{E}}=\frac{4 \pi \rho}{3} \sum_{\mathrm{j}=1}^{\mathrm{m}}\left(r_{\mathrm{j}}^{3}-r_{\mathrm{j}-1}^{3}\right) P_{\mathrm{E}}(j)
$$

$M_{\mathrm{E}}$ is therefore proportional to the cell density $\rho$. For example, when a local $\rho$ for a given cell type is 2000 cells $/ \mathrm{mm}^{3}$, the average $M_{\mathrm{E}}$ in this area will be 28 . From our data, $\rho$ values vary between 1600 cells $/ \mathrm{mm}^{3}$ for $\mathrm{SS}+$ cells in layer 4 to 3650 cells $/ \mathrm{mm}^{3}$ for $\mathrm{PV}+$ cells in layer 4 . Thus $M_{\mathrm{E}}$ varies between 22 for the lowest density of SS + cells and 51 for the highest density of PV + cells.

We cannot determine the exact relationship between $M_{\mathrm{E}}$ and $M$ using the information currently available. We can deduce, however, that $M$ is $>1$. Before introducing a general argument, we present a simple example. Consider a very large network in which each neuron is electrically coupled at random to $M$ other neurons. The closest, most strongly coupled cell pairs are highly likely to be coupled directly (cf. Tamás et al., 2000). Because $C C$ is, at most, $\sim 0.2$ for directly coupled pairs (Fig. $6 B$ ), then $C C$ for a pair 
$\mathbf{A}$
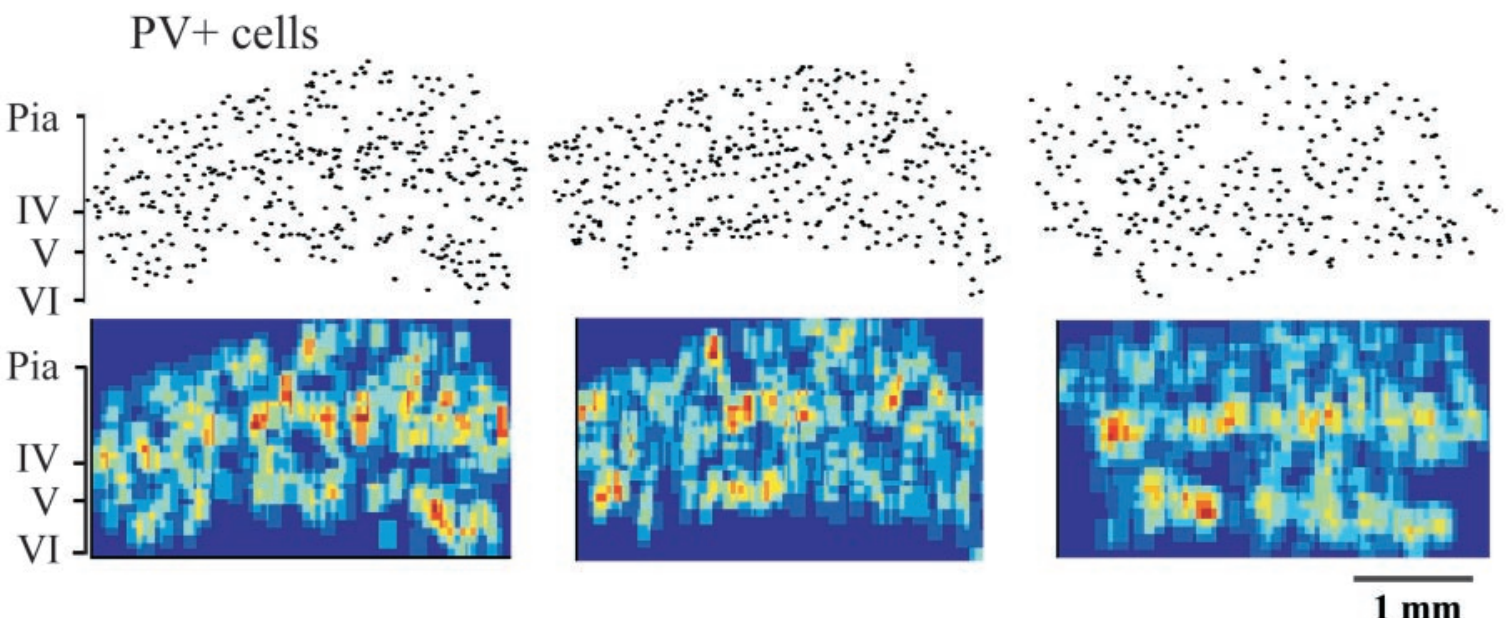

B
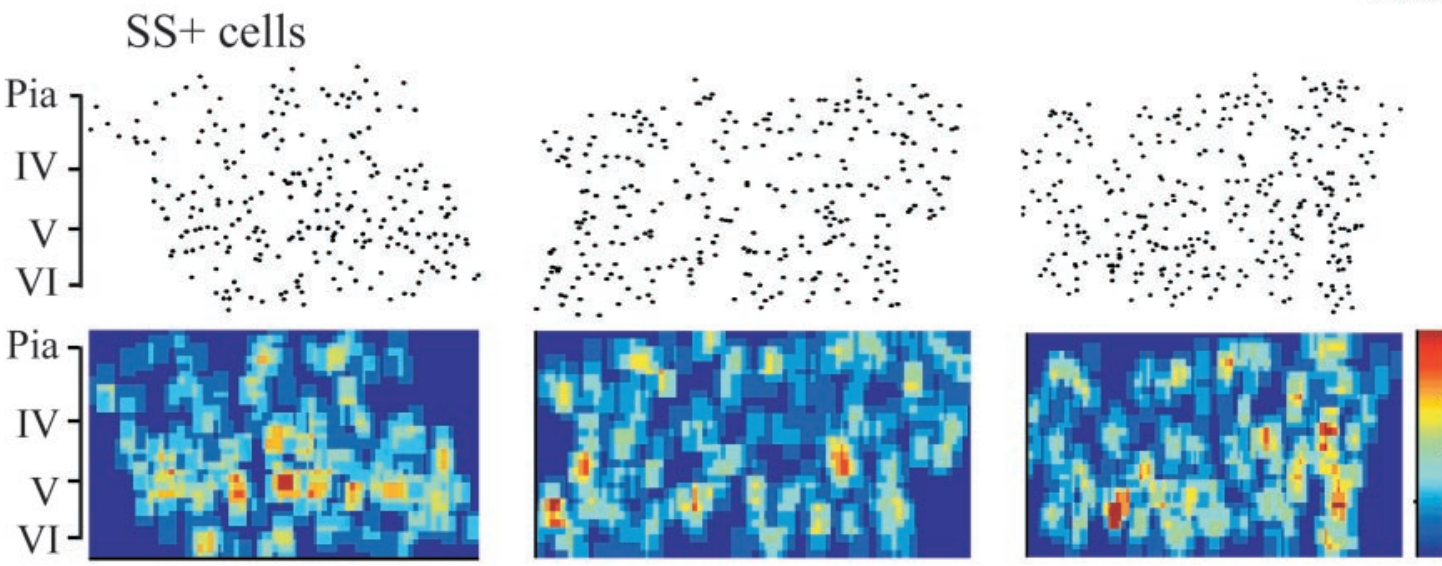

Figure 5. The spatial distribution of parvalbumin-positive cells $(A)$ and somatostatin-positive cells $(B)$. Three-example sections of each cell type are presented. The top panels depict the raw data. The bottom panels illustrate by color-coding the average cell density in bins of $30 \times 50 \mu \mathrm{m}$, deducted from a smoothing process of $4 \times 4$ such bins. Note that the maximal density observed was 0.5 cells/bin (red), thus eight cells in a rectangle of $120 \times 200 \mu \mathrm{m}$. The corresponding cortical laminas are marked to the left.

Figure 6. Histograms of the probability $P_{\mathrm{E}}$ that two cells are coupled $(A)$, the coupling coefficient $C C(B)$ and $P_{\mathrm{E}} \times C C(C)$ as a function of the distance between the cells. Data are based on recordings from pairs of both FS and LTS cells.
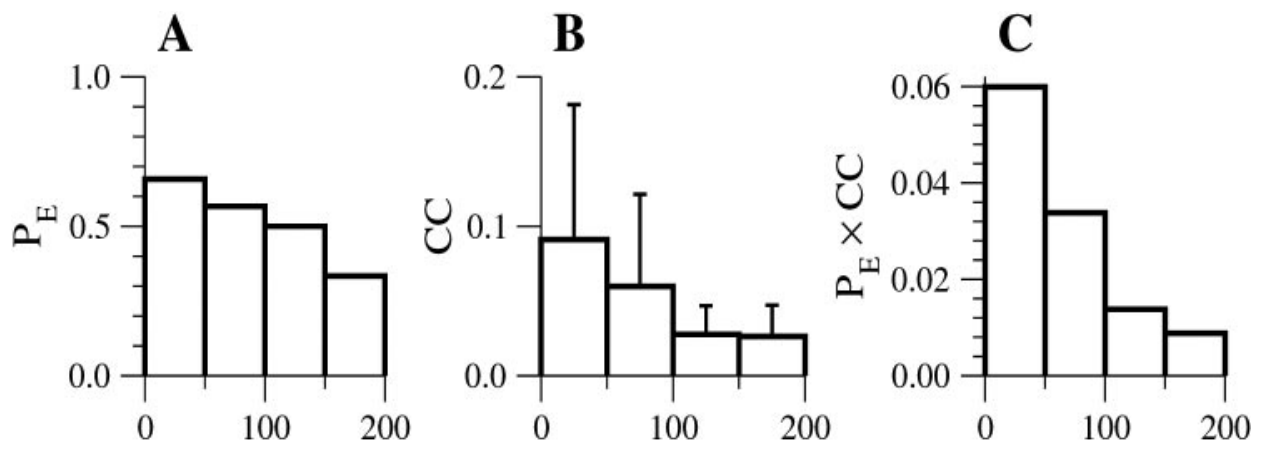

Distance between cells $(\mu \mathrm{m})$ indirectly coupled through one intermediary will be $\leq 0.04$, and with two intermediaries $C C$ will be $\leq 0.008$ (i.e., too small to measure readily). If only first-order coupling is detectable, then $M_{\mathrm{E}}=M$. If $M_{\mathrm{E}}$ is at most second-order coupling (i.e., only one intermediate cell) and if we neglect parallel routes of coupling, then $M_{\mathrm{E}}=M^{2}$. Thus, even for our lowest cell densities, $M_{\mathrm{E}}$ is $\sim 25$ and $M$ is between 5 and 25 .

But are the assumptions behind this simple example plausible? There are three main problems. First, a neuron can be indirectly coupled to other neurons through more than one intermediate neuron, thus creating a certain degree of overlap in the network, and yielding a smaller $M_{\mathrm{E}}$. Second, if each third-order neuron is coupled to more than one second-order neuron, it may have a coupling coefficient above the detection threshold, and this may cause an increase of $M_{\mathrm{E}}$. Third, our simple example does not consider dimensionality, whereas we know that neurons are coupled primarily to neighboring neurons. Assessing all of these factors demands a more thorough analysis. Nevertheless, we can make several biologically realistic assumptions: (1) neurons are connected at random with the probability given by $P(x)$; $(2) P$ 
A

Two cells

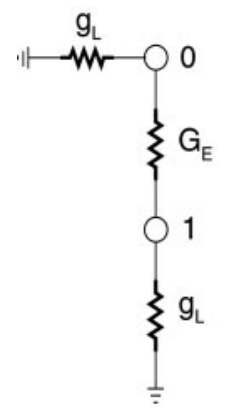

B

One cell coupled to M cells

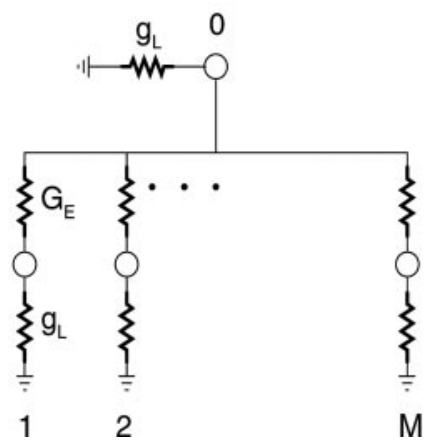

C

\section{1-d architecture}

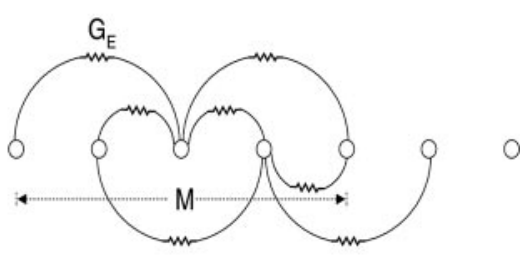

Figure 7. Architectures of network models. $A$, Two cells coupled by a gap junction with a conductance $G_{\mathrm{E}}$. $B$, A cell $(0)$ coupled to $M$ other cells. $C$, One-dimensional architecture. Each cell is coupled to $M / 2$ cells on its left and $M / 2$ cells on its right. Each coupling connection in $B$ and $C$ has a conductance $G_{\mathrm{E}}=g_{\mathrm{E}} / M$. Cells in all architectures have a leak conductance $g_{\mathrm{L}}$ (not specified in $C$ ).

does not depend on any other factor except $x$; and (3) the statistics of the electrical connections are homogeneous. To obtain a more general result, we need to use concepts borrowed from percolation theory. This theory describes how something (e.g., ionic current) flows through the random interconnections of lattices (e.g., networks of neurons) (Stauffer and Aharony, 1992). Using the above assumptions and percolation theory, one can show that if $M<1$, each neuron is coupled (directly or indirectly) only to a small number of other neurons, and $M_{\mathrm{E}}$ is not much larger than 1. Because our experimental results show that $M_{\mathrm{E}}$ is of the order of a few tens, $M$ should be $>1$. If $M>1$, the same theory tells us that almost all of the neurons belong to one large connected network, or syncytium, in which all cells are coupled to each other through other cells that belong to the network (Erdös and Rěnyi, 1960; Traub et al., 1999). This analysis cannot exclude cases in which electrical coupling exists only between neurons within spatially restricted patches. However, assuming a uniform likelihood that dendrites of same-type interneurons will create electrical synapses when they are adjacent, the cellular distribution as revealed by immunohistochemistry does not support such inhomogeneity within the somatosensory area.

\section{Models of electrically coupled networks}

The density of electrical coupling within a cell network will have important consequences for the estimated values of certain biophysical properties. In particular, conductances attributable to electrical coupling will add to membrane conductances, and significant errors can be made if network effects are not taken into account. In the following analysis, we will estimate the contribution of electrical coupling to the input conductances of each cell as measured experimentally. Two parameters in particular are likely to be affected: $g_{\mathrm{L}}$, the intrinsic leak conductance of each cell (i.e., the leak conductance of the non-gap junctional membrane), and $G_{\mathrm{E}}$, the strength of each electrical connection between two neurons. To estimate these values, one has to assume a model of the network architecture. We will first examine how these biophysical parameters depend on the specific architecture of the network, and then suggest a method to estimate them from data that can be generated experimentally. All network architecture models can be represented by the following steady-state equations (for $i$ from 1 to $N$ ):

$$
-g_{\mathrm{L}} V_{\mathrm{i}}-G_{\mathrm{E}} \sum_{\mathrm{j}=1}^{\mathrm{N}} J_{\mathrm{ij}}\left(V_{\mathrm{i}}-V_{\mathrm{j}}\right)+I_{\mathrm{i}}=0,
$$

where $V_{\mathrm{i}}$ is the voltage of the $i^{\text {th }}$ neuron and, at the neuronal rest state $V_{\mathrm{i}}=0, g_{\mathrm{L}}$ is the leak conductance, $G_{\mathrm{E}}$ is the coupling conductance between any two cells, and $I_{\mathrm{i}}$ is the current injected into the $i^{\text {th }}$ neuron. For simplicity, we consider models without heterogeneity: all of the neurons have the same $g_{\mathrm{L}}$ and all the existing coupling strengths are $G_{\mathrm{E}}$. Because electrical synapses are usually symmetrical (i.e., the coupling conductance from cell A to cell B is equal to the coupling conductance from cell B to cell A) (Galarreta and Hestrin, 2001), the matrix $J_{\mathrm{ij}}$ is symmetric such that $J_{\mathrm{ij}}=J_{\mathrm{ji}} . J_{\mathrm{ij}}$ is 1 if electrical coupling exists between neurons $i$ and $j$, and is zero otherwise. We consider cases in which constant current is injected to the neuron with an index $i=0$ only. Summing Equation 3 over all of the neurons, we obtain

$$
g_{\mathrm{L}}=\frac{I_{0}}{\sum_{\mathrm{i}} V_{\mathrm{i}}}
$$

Next we examine a few simple network architectures. We start with a model that has only two cells and then show that the influence of the network should be considered by using more realistic architectures.

\section{The two-cell model}

Traditionally, the coupling conductance between two cells, $G_{\mathrm{E}}$, has been calculated from the measured coupling coefficient, $C C$, assuming a two-cell model (Bennett, 1977). We consider here the simple case where the two cells are identical. This architecture (Fig. 7A) includes two cells, each with an input conductance $g_{\mathrm{L}}$ (resistance $R_{\mathrm{L}}=1 / g_{\mathrm{L}}$ ), which are coupled through a resistor $R_{\mathrm{E}}$ (conductance $G_{\mathrm{E}}=1 / R_{\mathrm{E}}$ ). The cells have indices 0 and 1 . Step current $I_{0}$ is injected into cell 0 . The coupling coefficient in the steady state is $C C_{\mathrm{i}}=V_{\mathrm{i}} / V_{0}$ (for $\left.i \neq 0\right)$. The conductance $G_{\mathrm{E}}$ can be estimated from the following relationship:

$$
G_{\mathrm{E}}=g_{\mathrm{L}} \frac{C C_{1}}{1-C C_{1}}
$$


For $G_{\mathrm{E}} \ll g_{\mathrm{L}}$ (and therefore $V_{1} \ll V_{0}$ ), Equations 4 and 5 become: $g_{\mathrm{L}}=I_{0} / V_{0}, G_{\mathrm{E}}=g_{\mathrm{L}} \times C C_{1}$.

However, this model does not take into account the fact that each cell may be coupled to many other cells. Obviously, the data we described for networks of neocortical interneurons require more elaborate models.

\section{One cell coupled to $\mathrm{M}$ other cells}

In this architecture (Fig. $7 B$ ), cell number 0 is electrically coupled to $M$ other cells, which are not coupled to each other. It is considerably more realistic than the two-cell model, because we concluded above that $M$ is much greater than 1 . The total coupling conductance on the $0^{\text {th }}$ cell is $g_{\mathrm{E}}=M G_{\mathrm{E}}$. The steady-state voltages of cells in response to current injection into cell 0 are given by the following equations:

$$
\begin{gathered}
\frac{I_{0}}{V_{0}}=g_{\mathrm{L}}+\frac{g_{\mathrm{L}} g_{\mathrm{E}}}{g_{\mathrm{L}}+g_{\mathrm{E}} / M} \\
V_{\mathrm{i}}=\frac{g_{\mathrm{E}} / M}{g_{\mathrm{L}}+g_{\mathrm{E}} / M} V_{0} ; i=1 . . M
\end{gathered}
$$

From Equation 7, one can calculate $g_{\mathrm{E}} / g_{\mathrm{L}}$ knowing $V_{\mathrm{i}}$ and $V_{0}$ :

$$
g_{\mathrm{E}} / g_{\mathrm{L}}=M C C_{\mathrm{i}} /\left(1-C C_{\mathrm{i}}\right)
$$

For large $M$, these equations become: $I_{0} / V_{0}=g_{\mathrm{L}}+g_{\mathrm{E}}$ and $V_{\mathrm{i}}=$ $g_{\mathrm{E}} V_{0} /\left(M g_{\mathrm{L}}\right)$.

As we show below (see Appendix B), the sum $\Sigma_{i \neq 0} C C_{i}$ can be calculated from experimental data and is useful for estimating network parameters. From Equation 8, this sum can be computed by:

$$
\sum_{\mathrm{i} \neq 0} C C_{\mathrm{i}}=\frac{g_{\mathrm{E}} / g_{\mathrm{L}}}{1+g_{\mathrm{E}} /\left(M g_{\mathrm{L}}\right)}
$$

The sum is approximately equal to $g_{\mathrm{E}} / g_{\mathrm{L}}$ for large $M$ or small $g_{\mathrm{E}}$, and we show below that under these conditions, one can estimate this ratio experimentally.

What happens if we try to estimate $g_{\mathrm{L}}$ (the nonjunctional membrane conductance) and $g_{\mathrm{E}}$ (the total junctional conductance) for one cell coupled to $M$ other cells but use the traditional approach that assumes the simple two-cell model? The two-cell model makes the approximation $g_{\mathrm{L}}=I_{0} / V_{0}$. If we take into account a large $M$, Equation 6 tells us that $I_{0} / V_{0}=g_{\mathrm{L}}+g_{\mathrm{E}}$. Hence, our error is a factor of $\left(g_{\mathrm{L}}+g_{\mathrm{E}}\right) / g_{\mathrm{L}}$, and this error biases the calculation of both $g_{\mathrm{L}}$ and $g_{\mathrm{E}}$ upward. For example, if $g_{\mathrm{L}}=g_{\mathrm{E}}$, the error is a factor of 2 . Even if the coupling conductance $G_{\mathrm{E}}$ (between two cells) is relatively small, the value of the total coupling conductance $g_{\mathrm{E}}=M G_{\mathrm{E}}$ can be of the same order as the leak conductance of the cell, $g_{\mathrm{L}}$. Using the two-cell model can therefore lead to unacceptably large errors.

\section{Networks with one-dimensional architecture}

The two architectures described above are too simplistic, but they do demonstrate that network effects should be considered when one estimates $g_{\mathrm{L}}$ and $g_{\mathrm{E}}$. In practice, of course, we know that not all the neurons are directly coupled to the recorded neurons. Furthermore, as shown in Figure 6, the probability that two cells are coupled depends strongly on the distance between them. Therefore, we next consider a model with spatially decaying connectivity.

This architecture is one-dimensional, a long chain of neurons,

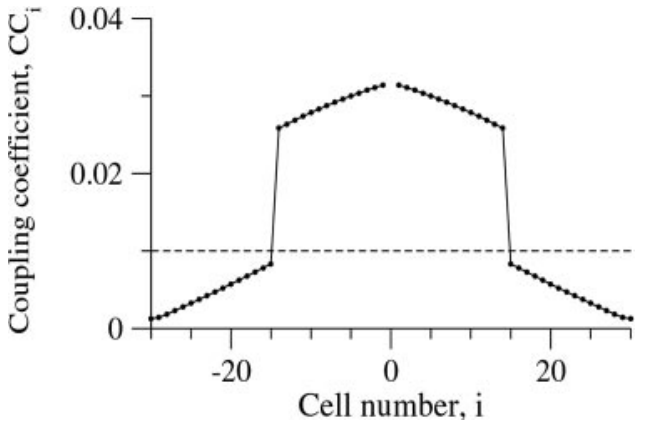

Figure 8. The coupling coefficient, $C C_{\mathrm{i}}$, as a function of the cell number $i$ for a one-dimensional architecture with $M=28$ and $g_{\mathrm{E}} / g_{\mathrm{L}}=1$. The values were computed either by solving Equation 3 or by numerical integration of Equation 11; the two results are equal. Note the jump in $C C_{\mathrm{i}}$ between cells 14 and $15(i=M / 2$ and $i=M / 2+1)$. The dashed line denotes the confidence level of $C C=0.01$.

that stretches from $-N / 2$ to $N / 2$, where $N \gg M$. Each neuron has an index $i$ and each is directly coupled to $M$ other neurons that are arrayed symmetrically to either side. Thus, the cell at $i=0$ is coupled to cells $j=-M / 2 \ldots 0 \ldots M / 2$ (Fig. $7 C)$. Cells near the edges are connected to a number of neurons that is smaller than $M$. The network is studied for large $N$. The version of Equation 3 for this system is

$$
-g_{\mathrm{L}} V_{\mathrm{i}}-\frac{g_{\mathrm{E}}}{M_{\mathrm{j}=-\mathrm{M} / 2}} \sum_{\substack{\mathrm{j} \neq 0 \\ \mathrm{M} / 2}}\left(V_{\mathrm{i}}-V_{\mathrm{i}+\mathrm{j}}\right)+I_{\mathrm{i}}=0 ;-N / 2<i<N / 2
$$

The stimulus current $I_{\mathrm{i}}$ is $I_{0}$ for $i=0$, and it is 0 otherwise. Using Fourier series, we obtain

$$
V_{\mathrm{i}}=\frac{I_{0}}{2 \pi} \int_{0}^{2 \pi} d \theta \frac{\cos (i \theta)}{g_{\mathrm{L}}+\frac{2 g_{\mathrm{E}}}{M} \sum_{\mathrm{j}=1}^{\mathrm{M} / 2}[1-\cos (j \theta)]}
$$

We cannot evaluate the integral in Equation 11 exactly for $M>$ 2 , and instead compute it numerically. An example is shown in Figure 8 , where we use the parameters $M=28$ (the value derived from a typical cell density of 2000 cells $/ \mathrm{mm}^{3}$ ); $M$ is close to $M_{\mathrm{E}}$, and $g_{\mathrm{E}}=g_{\mathrm{L}}$. When current $I_{0}$ is injected into the center cell, the voltage $V_{\mathrm{i}}$ decreases gradually to cells $i=-14$ and 14 (i.e., cells $-M / 2$ and $M / 2$ ) and then drops sharply at cells $i=-15$ and 15 , after which it decreases gradually again. These sharp jumps of $V_{\mathrm{i}}$ occur because neuron number 14 (or $M / 2$ ) is directly coupled to the injected neuron $(i=0)$, but neuron number 15 (or $M / 2+1)$ is only indirectly coupled to it. Interestingly, when $g_{\mathrm{E}}$ and $g_{\mathrm{L}}$ have similar values, the values of $V_{\mathrm{i}}$ for $i$ that are just larger than $M / 2$ are not negligible at all. For example, for $g_{\mathrm{E}}=g_{\mathrm{L}}$ and $M=28$, $V_{15} / V_{14}=0.32$. Yet, for this specific example, indirect connections fall below the experimental confidence level.

The sum $\Sigma_{\mathrm{i} \neq 0} C C_{\mathrm{i}}$, which is useful for calculating $g_{\mathrm{E}}$, can be calculated exactly in two limiting cases. In the limit of large $M$, we show in Appendix A that

$$
\lim _{M \rightarrow \infty} \sum_{\mathrm{i} \neq 0} C C_{\mathrm{i}}=\frac{g_{\mathrm{E}}}{g_{\mathrm{L}}}
$$

Namely, $\left(g_{\mathrm{L}} / \mathrm{g}_{\mathrm{E}}\right) \Sigma_{i \neq 0} C C_{\mathrm{i}}=1$ for $M \rightarrow \infty$. Similarly, we can show that $\Sigma_{\mathrm{i} \neq 0} C C_{\mathrm{i}}=g_{\mathrm{E}} / g_{\mathrm{L}}$ for $g_{\mathrm{E}} / g_{\mathrm{L}} \ll 1$. 
Figure 9. Effects of network architectures on $\left(g_{\mathrm{J}} / g_{\mathrm{E}}\right) \Sigma_{\mathrm{i} \neq 0}$ $C C_{\mathrm{i}} \cdot A$, The dependence of $\left(g_{\mathrm{L}} / g_{\mathrm{E}}\right) \sum_{\mathrm{i} \neq 0} C C_{\mathrm{i}}$ at steady state on $M$ for one-dimensional architecture and three values of $g_{\mathrm{E}} / g_{\mathrm{L}}$ : 0.5 (solid line), 1 (dotted line), and 2 (dashed line). $B$, The dependence of $\left(g_{\mathrm{L}} / g_{\mathrm{E}}\right) \Sigma_{\mathrm{i} \neq 0} C C_{\mathrm{i}}$ at steady state on $g_{\mathrm{E}} / g_{\mathrm{L}}$ for three architectures: one-dimensional architecture (solid line), one cell coupled to $M$ other cells (dotted line), and twodimensional architecture (dashed line). $M=28$ for all the architectures. Calculations for the one-dimensional architecture were carried out as in Figure 8. Equation 9 was used for calculating $C C$ for the architecture with one cell coupled to $M$ other cells. In the two-dimensional architecture, cells are located on a two-dimensional grid, at positions $x=(i \Delta, j \Delta)$, where $i$ and $j$ are integers and $\Delta$ is the grid unit length. Cells at positions $\left(i_{1}, j_{1}\right)$ and $\left(i_{2}, j_{2}\right)$ are coupled if $\sqrt{\left(i_{1}-i_{2}\right)^{2}+\left(j_{1}-j_{2}\right)^{2}} \leq 3$. Calculations were performed by solving Equation 3.

What is the value of $\Sigma_{\mathrm{i} \neq 0} C C_{\mathrm{i}}$ in a parameter regime not close to these limits? The dependence on connectivity, $M$, for three values of $g_{\mathrm{E}} / g_{\mathrm{L}}(0.5,1$, and 2$)$ is shown in Figure $9 A$. Figure $9 A$ demonstrates that Equation 12 holds for large $M$. Moreover, the dependence of $\Sigma_{\mathrm{i} \neq 0} C C_{\mathrm{i}}$ on $M$ is weak, unless $M$ is small $(<10)$. Figure $9 B$ demonstrates further that for a specific $M$ in any of the architectures examined, the value of $\left(g_{\mathrm{L}} / g_{\mathrm{E}}\right) \sum_{\mathrm{i} \neq 0} C C_{\mathrm{i}}$ decreases gradually and slowly from 1 as a function of $g_{\mathrm{E}} / g_{\mathrm{L}}$. The solid line represents the one-dimensional architecture and $M=28$, as examined in the example above. Even for $g_{\mathrm{E}} / g_{\mathrm{L}}=2$, the value of $\left(g_{\mathrm{L}} / g_{\mathrm{E}}\right) \Sigma_{\mathrm{i} \neq 0} C C_{\mathrm{i}}$ is 0.95 , demonstrating that the value of the sum $\sum_{\mathrm{i} \neq 0} C C_{\mathrm{i}}$ is close to $g_{\mathrm{E}} / g_{\mathrm{L}}$ even beyond the two limiting cases described above.

We also consider a two-dimensional model, in which neurons are located on a two-dimensional lattice and are electrically connected if the distance between them is smaller than a certain value. The behavior of this model is found to be similar to the behavior of the one-dimensional model, as represented by the dashed line in Figure 9B. This line is only slightly above the line for the one-dimensional model with the same $M$. For comparison, we present also the dependence of $\left(g_{\mathrm{L}} / g_{\mathrm{E}}\right) \Sigma_{\mathrm{i} \neq 0} C C_{\mathrm{i}}$ for $M=28$ as a function of $g_{\mathrm{E}} / g_{\mathrm{L}}$ for the architecture of one neuron coupled to $M$ other neurons (Eq. 9). This line is only slightly below the line for the one-dimensional model with the same $M$.

Together, the important result of this analysis is that the value of $\left(g_{\mathrm{L}} / g_{\mathrm{E}}\right) \Sigma_{\mathrm{i} \neq 0} C C_{\mathrm{i}}$ depends only weakly on the model architecture. For all the architectures we examined, $\left(g_{\mathrm{L}} / g_{\mathrm{E}}\right) \sum_{\mathrm{i} \neq 0} C C_{\mathrm{i}}$ has the asymptotic value of 1 for large $M$ or small $g_{\mathrm{E}} / g_{\mathrm{L}}$, and for $g_{\mathrm{E}} \sim$ $g_{\mathrm{L}}$, the difference between one architecture and another is $<5 \%$. Therefore, we propose to use the sum $\Sigma_{\mathrm{i} \neq 0} C C_{\mathrm{i}}$ for estimating $g_{\mathrm{E}} / g_{\mathrm{L}}$.

\section{Estimating $\boldsymbol{g}_{\mathrm{L}}$ and $\boldsymbol{g}_{\mathrm{E}}$ from measurements}

Unfortunately, we cannot develop a method for estimating $G_{\mathrm{E}}(i$, $j$ ) for a specific connection between two specific neurons, $i$ and $j$, in the network. In many cases, however, the dynamic behavior of neuronal networks can be described by knowing $g_{\mathrm{E}}$ and $g_{\mathrm{L}}$ (Chow and Kopell, 2000). We show above that the sum $\sum_{\mathrm{i} \neq 0} C C_{\mathrm{i}}$ can be used for estimating the ratio between $g_{\mathrm{E}}$ and $g_{\mathrm{L}}$. Furthermore, we can use the sum $\Sigma_{\mathrm{i}} V_{\mathrm{i}}$ to estimate $I_{0} / g_{\mathrm{L}}$ (Eq. 4). It is obviously impractical to measure the sums $\Sigma_{\mathrm{i}} V_{\mathrm{i}}$ and $\Sigma_{\mathrm{i} \neq 0} C C_{\mathrm{i}}$ directly in experiments, because of the limited number of neurons that can be recorded. Instead, we have developed a method for estimating these values, and therefore for estimating $g_{\mathrm{E}}$ (the total conductance of a cell from all of its electrical connections) and $g_{\mathrm{L}}$ (the intrinsic leak conductance of a cell), by averaging over many experiments, and we present it in detail in Appendix B.
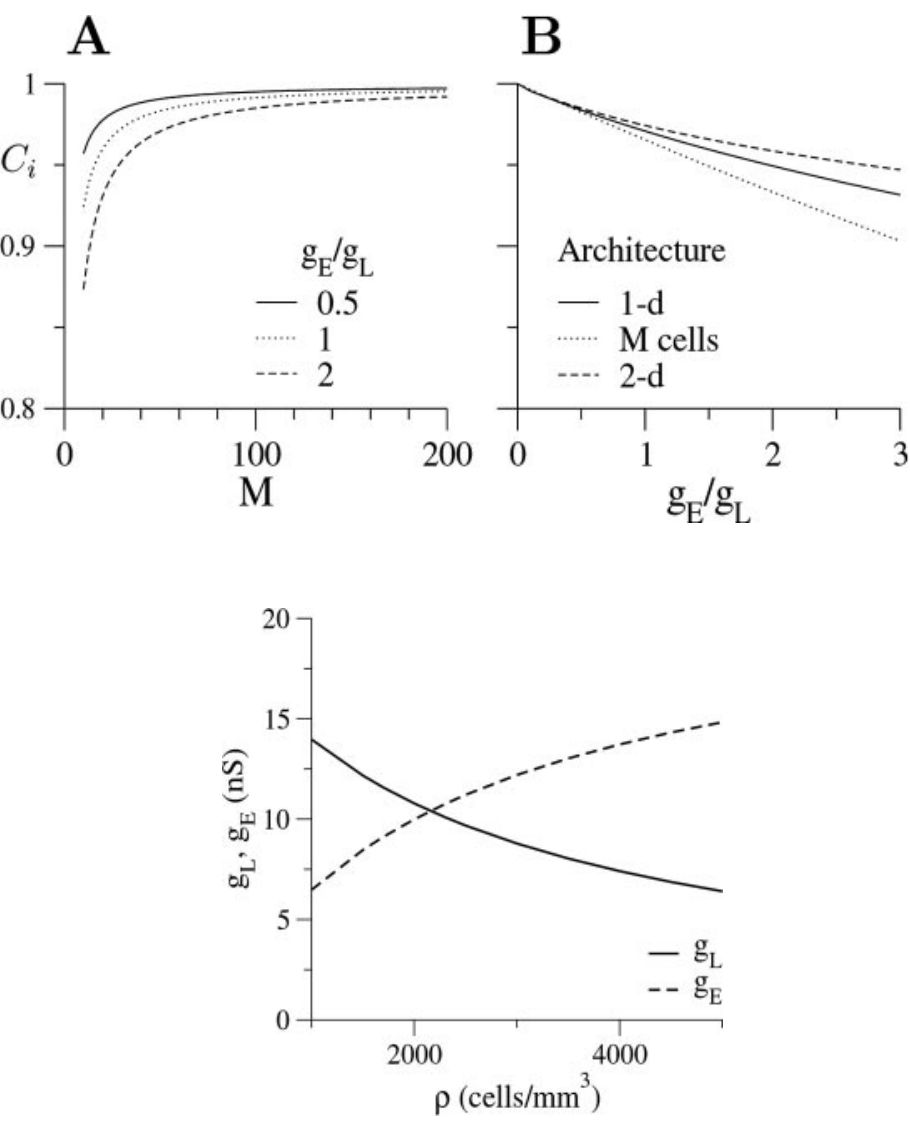

Figure 10. The dependence of $g_{\mathrm{L}}$ (solid line) and $g_{\mathrm{E}}$ (dashed line) on the cell density $\rho$, calculated using Equations B3 and B4, for the data obtained experimentally.

For a given set of dual intracellular measurements, the estimations for $g_{\mathrm{E}}$ and $g_{\mathrm{L}}$ depend only on the cell density $\rho$. As $\rho$ increases, $g_{\mathrm{L}}$ decreases and $g_{\mathrm{E}}$ increases (Fig. 10). For a typical $\rho$ of 2000 cells $/ \mathrm{mm}^{3}, g_{\mathrm{E}}$ contributes approximately one-half of the measurable input conductance $\left(g_{\mathrm{L}}=11 \mathrm{nS}\right.$ and $\left.g_{\mathrm{E}}=10 \mathrm{nS}\right)$. For the extreme case of $\rho$ close to 4000 cells $/ \mathrm{mm}^{3}, g_{\mathrm{E}} / g_{\mathrm{L}}$ is close to 2 . In every reasonable scenario, the values of $g_{\mathrm{E}}$ and $g_{\mathrm{L}}$ are of the same order of magnitude. The fact that the values of $g_{\mathrm{L}}$ and $g_{\mathrm{E}}$ are similar means that if the membrane conductance of the cell, $g_{\mathrm{L}}$, is estimated naively as $I_{0} / V_{0}$, as it generally is in systems of uncoupled cells, the estimated value of $g_{\mathrm{L}}$ would be approximately twice the correct value.

What are the implications of these values on the values of $G_{\mathrm{E}}$ ? Although we cannot measure $G_{\mathrm{E}}$ directly, we can estimate the order of magnitude of its average value. Considering an average value of $\rho=2000$ cells $/ \mathrm{mm}^{3}$, we have estimated that $g_{\mathrm{E}}=10 \mathrm{nS}$ and $M$, the number of neurons that are directly coupled to each neuron, is between $5\left(\sqrt{M_{\mathrm{E}}}\right)$ and $28\left(M_{\mathrm{E}}\right)$. Thus, for this cell density, $G_{\mathrm{E}}$ varies between $0.36 \mathrm{nS}$ and $2 \mathrm{nS}$.

\section{DISCUSSION}

We have investigated the spatial distribution of two coupled groups of neocortical interneurons. From our morphological studies we conclude that the somadendritic morphology of FS and LTS cells is similar, with $\sim 80 \%$ of the dendritic trees $<200 \mu \mathrm{m}$ from the soma. However, FS and LTS cells differ considerably in their densities and laminar distribution. Electrophysiological recordings from same-type neuronal pairs demonstrated that the 
probability of electrical coupling and the coupling coefficient declined with the distance between somata. Electrical coupling never occurred when the distance between somata was $>200 \mu \mathrm{m}$. Our computations suggest that a single neuron is electrically coupled to tens of other neurons, implying that each type of interneuron forms a highly interconnected network over large cortical areas.

\section{Estimating parameters of electrical coupling}

The strength of electrical coupling between two cells is easily calculated when these cells are isolated (Bennett, 1977). For lack of better methods, the "two-cell model" has usually been used to determine the electrical coupling strength between cell pairs even in highly connected systems (Gibson et al., 1999; Galarreta and Hestrin, 2001). However, this method can provide a good approximation only if the effects on the recorded cell pair of other, unrecorded, coupled cells are minimal, namely when $g_{\mathrm{E}}$ is small compared with $g_{\mathrm{L}}$. Here we show that for the networks of neocortical interneurons, $g_{\mathrm{E}}=M G_{\mathrm{E}}$ is not small in comparison with $g_{\mathrm{L}}$; rather, the two have similar magnitudes. The two-cell model cannot be used in these systems because it does not take into account two important factors: (1) the increase of the effective leak conductance $\left(I_{0} / V_{0}\right)$ because of the current flow to other neurons, and (2) the fact that electrical coupling between two cells can be mediated through other neurons.

We present here an approach for estimating the average membrane conductance, $g_{\mathrm{L}}$, and the average total electrical conductance attributable to electrical junctions onto a single neuron, $g_{\mathrm{E}}$, based on a large number of measurements and on solving the voltage profiles in several models. We estimate that the $g_{\mathrm{L}}$ and $g_{\mathrm{E}}$ of inhibitory interneurons in the neocortex are of the same order of magnitude (i.e., gap junctions contribute approximately onehalf of the input conductance measured during electrophysiological experiments. The exact ratio between $g_{\mathrm{L}}$ and $g_{\mathrm{E}}$ depends on the density of the cells within a coupled neuronal network.

A recent study of neocortical interneurons from connexin36 (Cx36) knock-out (KO) mice demonstrated that, indeed, the mean input resistance of cells in the $\mathrm{KO}$ is $\sim 30-40 \%$ higher than that of wild-type cells (Deans et al., 2001). This increase is not as high as our theoretical results predict, but it is also very likely that the KO cells achieve some partial compensation of membrane conductance during development. Nevertheless, this finding supports our prediction that gap junctions provide a major contribution to the total measured conductance of these cells.

The architecture of electrically coupled networks of neurons has been studied mostly in noncortical tissues, such as the retina. There, the effect of gap junctions was examined using twodimensional architectures in which each neuron is coupled only to its few nearest neighbors (hence $M=4$ for a rectangular grid) (Naka and Rushton, 1967; Gold, 1979; Poznanski and Umino, 1997). Analysis reveals that when current is injected into a cell within such a nearest-neighbor architecture, the size of voltage deflections in other cells decreases almost exponentially with the distance from the injected cell. In contrast, each cell in our system is coupled to tens of other cells, so models with large $M$ are more appropriate. In such models, voltage deflections decay only weakly over short distances, in agreement with our experimental data. Interestingly, a study of electrical coupling between neurons in the inferior olive revealed spatial coupling patterns very similar to ours (Devor and Yarom, 2002): neurons in the olive are highly likely to be coupled if their intersomatic distance is $<100 \mu \mathrm{M}$, the dependence of $P_{\mathrm{E}}$ and $C C$ on distance is comparable with what we find here, and the number of connected cells is estimated to be between 10 and 40. It will be interesting to perform similar investigations in other parts of the CNS to test the generality of these rules about the architecture of electrical networks.

\section{Potential sources of bias}

Our calculations have several potential sources of bias. First, the cell density was calculated from random sections and corrected only for shrinkage of the slice thickness. Our estimate is smaller than the density of PV + cells in another study using stereometry ( $\sim 7000$ cells $/ \mathrm{mm}^{3}$; Ren et al., 1992). However, the relative ratio of $\mathrm{PV}+$ neurons in that study is $\sim 54 \%$ of all GABAergic cells, which is much higher than most other estimates in rodent somatosensory cortex (Gonchar and Burkhalter, 1997, Kawaguchi and Kubota, 1997). It is also possible that the probability of coupling (Fig. 6A) was underestimated because some dendritic arbors were severed by the slicing procedures. The signal-to-noise ratio prevents the detection of the least effective connections. All of these technical limitations are likely to bias our results toward weaker electrical coupling. Even so, our modeling results are robust to our experimental results and to a wide range of cell densities.

Another possible source of error arises from the relatively small electrophysiological sample from which the probability of connectivity was deduced. Nevertheless, the probability data agree well with recent morphological data. Double-staining for Cx36 reporter genes and specific markers of interneurons suggested that not all $\mathrm{PV}+$ and $\mathrm{SS}+$ interneurons express $\mathrm{Cx} 36$, and the proportion of double-labeled cells was similar to the proportion of electrophysiologically coupled neighboring cells in the sample (Dean et al., 2001).

Our modeling work does not consider heterogeneities in $g_{\mathrm{L}}$, variations in the electrical coupling strength $G_{\mathrm{E}}$, and sparse connectivity in which neurons are not necessarily coupled to each other, even if they are adjacent. These factors could bias our estimates of $g_{\mathrm{E}}$ and $g_{\mathrm{L}}$. Qualitative estimation of the bias will require more theoretical work on models with relatively elaborate architectures. Preliminary modeling results with sparse and spatially decaying connectivity (data not shown) indicate that the effects of sparseness on the estimated values of $g_{\mathrm{E}}$ and $g_{\mathrm{L}}$ are small.

\section{Functional implications}

Electrical coupling is likely to affect both the properties of single cells and the properties of cellular networks as a whole. Gap junctions increase the effective leak conductance of neurons and thus decrease their passive time constants (Andreu et al., 2000). This may cause faster reaction times to stimulus-induced changes and may make firing times follow the membrane potential more faithfully. The minimal current needed to initiate firing will increase with electrical coupling as well, and the frequencycurrent dependence of a neuron will be shifted to the right, (i.e., to larger current regimes) (Holt and Koch, 1997).

At the network level, it has been suggested that a population of inhibitory neurons in vivo synchronizes its spikes and entrains populations of excitatory neurons via their inhibitory chemical synapses (Buzsáki et al., 1983). Data from brain slices do indeed confirm that this scenario can occur under certain conditions (Whittington et al., 1995, Jefferys et al., 1996; Draguhn et al., 1998). Theoretical work, however, has shown that synchronization through inhibition has a fundamental limitation because of the joint effects of sparse connectivity and heterogeneity in the cellular intrinsic properties (Golomb and Hansel, 2000; Neltner et 
al., 2000; Golomb et al., 2001). Synchrony is destroyed by the heterogeneity of the network at weak inhibitory conductances and because of sparseness at strong inhibitory conductances. There is, therefore, only a restricted window of conductance strengths (if at all) in which network firing synchrony can be achieved by inhibition. Synchronization through electrical coupling is an alternative mechanism. Indeed, theoretical studies have most commonly claimed that strong electrical coupling in neuronal systems tends to increase spike synchronization (Traub et al., 2001); if it is weak, other patterns of synchrony may emerge (Chow and Kopell, 2000). In local networks, electrical coupling is a much more robust mechanism for spike synchronization than inhibitory connections (Golomb et al., 2001). Our study shows that the electrical coupling $\left(g_{\mathrm{E}}\right)$ between groups of interneurons is strong, and therefore electrical coupling may play an important role in synchronizing the firing patterns of interneurons.

Studies of LTS cells provide evidence for the spatial dimensions of coupled networks (Beierlein et al., 2000). When a network of LTS neurons is activated selectively with agonists, IPSPs become synchronized over distances of $\sim 400 \mu \mathrm{m}$. In connexin 36 knock-out mice, long-range synchrony is absent (Deans et al., 2001), implying that it is a coupling-dependent, collective network effect. These data are consistent with two of our conclusions: (1) the electrical coupling conductance $g_{\mathrm{E}}$ is relatively strong, and (2) interneurons form large, extensive electrically coupled networks. The fact that synchronization of IPSPs (and probably spikes) does not have a much larger correlation distance may be a result of extensive sparseness and heterogeneity of the network.

There may be other roles for large-scale, electrically connected networks of interneurons. In many cases, FS-type inhibitory neurons of the sensory neocortex have more broadly tuned receptive fields than regular-spiking neurons (Swadlow and Weyand, 1987; Simons and Carvell, 1989; Swadlow, 1989; Gibber et al., 2001); long-range electrical coupling among interneurons might account for this. Furthermore, the spread of activity through coupled networks of interneurons could create a "surround inhibition" effect around focal areas of activation.

\section{APPENDIX A: $\sum_{\mathbf{i} \neq 0} \boldsymbol{C C}_{\mathbf{i}}$ for large $\boldsymbol{M}$}

In this Appendix, we prove that for the one-dimensional architecture,

$$
\lim _{M \rightarrow \infty} \sum_{\mathrm{i} \neq 0} C C_{\mathrm{i}}=g_{\mathrm{E}} / g_{\mathrm{L}}
$$

We first note that, from Equation 4 and the definition of $C C_{\mathrm{i}}$,

$$
\frac{I_{0}}{g_{\mathrm{L}}}=\sum_{\mathrm{i}} V_{\mathrm{i}}=V_{0}\left(1+\sum_{\mathrm{i} \neq 0} C C_{\mathrm{i}}\right) .
$$

Therefore, Equation A1 is correct if we can prove that

$$
\lim _{M \rightarrow \infty} V_{0}=\frac{I_{0}}{g_{\mathrm{L}}+g_{\mathrm{E}}} .
$$

We start by computing the sum in Equation 11 and obtaining

$$
V_{0}=\frac{I_{0}}{2 \pi} \int_{0}^{2 \pi} d \theta \frac{1}{g_{\mathrm{L}}+g_{\mathrm{E}}-\frac{g_{\mathrm{E}}}{M}\left[\cos (M \theta / 2)-1+\frac{\sin (M \theta / 2) \sin (\theta)}{1-\cos (\theta)}\right]} .
$$

The first two terms in the square brackets are finite and go to zero after division by $M$. The third term diverges at $\theta=0$. We need to show that its contribution to the integral is as small as we wish, provided that $M$ is large enough. To do this, we first see that this term divided by $M$ is finite near 0 :

$$
\frac{\sin (M \theta / 2) \sin (\theta)}{M[1-\cos (\theta)]}=1+O\left(\theta^{2}\right)
$$

This term reaches maximum at $\theta=0$. For small $\theta$ values and large $M$, the term behaves as $2 \sin (M \theta / 2) /(M \theta)$. We choose a value $\theta_{0} \ll 2 \pi$ such that the contributions to the integral (Eq. A5) from the ranges $\left[0, \theta_{0}\right]$ and $\left[2 \pi-\theta_{0}, 2 \pi\right]$ are small. For the range $\left[\theta_{0}, 2 \pi-\theta_{0}\right]$, the term in Equation A5 is bounded:

$$
\left|\frac{\sin (M \theta / 2) \sin (\theta)}{M[1-\cos (\theta)]}\right| \leq \frac{1}{M}\left|\frac{\sin (\theta)}{1-\cos (\theta)}\right| \leq \frac{1}{M}\left|\frac{\sin \left(\theta_{0}\right)}{1-\cos \left(\theta_{0}\right)}\right| .
$$

The second inequality is a result of the fact that the function $\sin (\theta) /[1-\cos (\theta)]$ is monotonically decreasing in the interval $(0$, $2 \pi)$, and is antisymmetric around $\theta=\pi$. Hence, the contribution of the third term in the square brackets of Equation A4 can be made arbitrarily small by choosing a large enough $M$, and Equation A4 becomes Equation A3.

\section{APPENDIX B: Estimating $\boldsymbol{g}_{\mathrm{L}}$ and $\boldsymbol{g}_{\mathrm{E}}$}

In this appendix, we present a method for estimating the sums $\sum_{\mathrm{i}} V_{\mathrm{i}}$ and $\sum_{\mathrm{i} \neq 0} C C_{\mathrm{i}}$ by averaging over many experiments. Assuming homogeneous networks, we define $P_{\mathrm{E}}(x)$ as the probability that two cells at positions $x_{1}$ and $x_{2}=x_{1}+x$ are electrically coupled (in this appendix, $x$ means a three-dimensional coordinate). The sum $\Sigma_{\mathrm{i}} V_{\mathrm{i}}=V_{0}+\sum_{\mathrm{i} \neq 0} V_{\mathrm{i}}$, in response to a specific current $I_{0}$ is estimated to be

$$
[V(0)]_{\text {pop }}+\rho \int d x P_{\mathrm{E}}(x) V(x)
$$

where $[V(0)]_{\text {pop }}$ is the average of the membrane voltages over the entire neuronal population to which current is injected and $\rho$ is the cell density. By including the probability $P_{\mathrm{E}}(x)$, we take into account in the integral in Equation B1 only the voltage of neurons that show response to the current injected to neuron number " 0 ." Similarly, the sum $\sum_{\mathrm{i} \neq 0} C C_{\mathrm{i}}$ can be described by:

$$
\rho \int d x P_{\mathrm{E}}(x) C C(x)
$$

The integrals in Equations B1 and B2 are approximated by sums over shells, such that in each shell the values of $P_{\mathrm{E}}$ and $C C$ are those given in Figure 6 . The parameters $g_{\mathrm{L}}$ and $g_{\mathrm{E}}$ can be obtained from the following equations:

$$
\begin{gathered}
I_{0} / g_{\mathrm{L}}=\sum_{\mathrm{i}} V_{\mathrm{i}}=\left[V_{0}\right]_{\text {pop }}+\frac{4 \pi \rho}{3} \sum_{\mathrm{j}=1}^{\mathrm{m}}\left(r_{\mathrm{j}}^{3}-r_{\mathrm{j}-1}^{3}\right) P_{\mathrm{E}}(j) V(j), \\
g_{\mathrm{E}} / g_{\mathrm{L}}=\sum_{\mathrm{i} \neq 0} C C_{\mathrm{i}}=\frac{4 \pi \rho}{3} \sum_{\mathrm{j}=1}^{\mathrm{m}}\left(r_{\mathrm{j}}^{3}-r_{\mathrm{j}-1}^{3}\right) P_{\mathrm{E}}(j) C C(j) .
\end{gathered}
$$

\section{REFERENCES}

Agmon A, Connors BW (1991) Thalamocortical responses of mouse somatosensory (barrel) cortex in vitro. Neuroscience 41:365-379. 
Akil M, Lewis DA (1992) Differential distribution of parvalbuminimmunoreactive pericellular clusters of terminal boutons in developing and adult monkey neocortex. Exp Neurol 115:239-249.

Andreu E, Fernández E, Louis E, Ortega G, Sánchez-Andrés JV (2000) Role of architecture in determining passive electrical properties in gap junction-connected cells. Pflügers Arch-Eur J Physiol 439:789-797.

Bayraktar T, Welker E, Freund TF, Zilles K, Staiger JF (2000) Neurons immunoreactive for vasoactive intestinal polypeptide in the rat primary somatosensory cortex: morphology and spatial relationship to barrelrelated columns. J Comp Neurol 420:291-304.

Beierlein M, Gibson JR, Connors BW (2000) A network of electrically coupled interneurons drives synchronized inhibition in neocortex. Nat Neurosci 3:904-910.

Benardo LS (1997) Recruitment of GABAergic inhibition and synchronization of inhibitory interneurons in rat neocortex. J Neurophysiol 77:3134-3144.

Benes FM, Lang N (2001) Two-dimensional versus three-dimensional cell counting: a practical perspective. Trends Neurosci 24:11-17.

Bennett MVL (1977) The nervous system, part I. In: Handbook of physiology, section 1 (Brookhart JM, Mountcastle VB, eds), pp 357416. Bethesda, MD: American Physiological Society.

Braitenberg V (1978) Cortical architectonics: general and areal. In: Architectonics of the cerebral cortex (Brazier MAB, Petche M, eds), pp 443-465. New York: Raven.

Buzsáki G, Leung L, Vanderwolf CH (1983) Cellular bases of hippocampal EEG in the behaving rat. Brain Res Brain Res Rev 6:139-171.

Chow CC, Kopell N (2000) Dynamics of spiking neurons with electrical coupling. Neural Comput 12:1643-1678.

Deans MR, Gibson JR, Sellitto C, Connors BW, Paul DL (2001) Synchronous activity of inhibitory networks in neocortex requires electrical synapses containing connexin36. Neuron 31:477-485.

Devor A, Yarom Y (2002) Electrotonic coupling in the inferior olivary nucleus revealed by simultaneous double patch recordings. J Neurophysiol, in press.

Draguhn A, Traub RD, Schmitz D, Jefferys JGR (1998) Electrical coupling underlies high-frequency oscillations in the hippocampus in vitro. Nature 394:189-192.

Erdös P, Rĕnyi A (1960) On the evolution of random graphs. Publ Math Inst Hung Acad Sci 5:17-61.

Galarreta M, Hestrin S (1999) A network of fast-spiking cells in the neocortex connected by electrical synapses. Nature 402:72-75.

Galarreta M, Hestrin S (2001) Electrical synapses between GABAreleasing interneurons. Nat Rev Neurosci 2:425-433.

Gibber M, Chen B, Roerig B (2001) Direction selectivity of excitatory and inhibitory neurons in ferret visual cortex. NeuroReport 12:2293-2296.

Gibson JR, Beierlein M, Connors BW (1999) Two networks of electrically coupled inhibitory neurons in neocortex. Nature 402:75-79.

Gold GH (1979) Photoreceptor coupling in retina of the toad, Bufo marinus. II. Physiology. J Neurophysiol 42:311-328.

Golomb D, Hansel D (2000) The number of synaptic inputs and the synchrony of large, sparse neuronal networks. Neural Comput 12:1095-1139.

Golomb D, Hansel D, Mato G (2001) Mechanisms of synchrony of neural activity in large networks. In: Handbook of biological physics, Vol 4: Neuro-informatics and neural modelling (Moss F, Gielen S, eds), pp 887-968. Amsterdam: Elsevier Science.

Gonchar Y, Burkhalter A (1997) Three distinct families of GABAergic neurons in rat visual cortex. Cereb Cortex 7:347-358.

Hendry SH, Jones EG, Emson PC, Lawson DE, Heizmann CW, Streit P (1989) Two classes of cortical GABA neurons defined by differential calcium binding protein immunoreactivities. Exp Brain Res 76:467-472.

Holt GR, Koch C (1997) Shunting inhibition does not have a divisive effect on firing rate. Neural Comput 9:1001-1013.

Jefferys JGR, Traub RD, Whittington MA (1996) Neural networks for induced "40 Hz" rhythms. Trends Neurosci 19:202-208.
Jin X, Mathers PH, Szabo G, Katarova Z, Agmon A (2001) Vertical bias in dendritic tress of non-pyramidal neocortical neurons expressing GAD67-GFP in vitro. Cereb Cortex 11:666-678.

Kawaguchi Y, Kubota Y (1997) GABAergic cell subtypes and their synaptic connections in rat frontal cortex. Cereb Cortex 7:476-486.

Kosaka T (1983) Gap junctions between nonpyramidal cell dendrites in the rat hippocampus (CA1 and CA3 regions). Brain Res 277:347-351.

Kosaka T, Hama K (1985) Gap junctions between non-pyramidal cell dendrites in the rat hippocampus (CA1 and CA3 regions): a combined Golgi-electron microscopy study. J Comp Neurol 231:150-161.

Kubota Y, Hattori R, Yui Y (1994) Three distinct subpopulations of GABAergic neurons in rat frontal agranular cortex. Brain Res 649:159-73

McMullen NT, Smelser CB, Rice FL (1994) Parvalbumin expression reveals a vibrissa-related pattern in rabbit SI cortex. Brain Res 660:225-231.

Naka KI, Rushton W (1967) The generation and spread of S-potentials in fish (cyprinidae). J Physiol (Lond) 192:437-461.

Neltner L, Hansel D, Mato G, Meunier C (2000) Synchrony in heterogeneous networks of spiking neurons. Neural Comput 12:1607-1641.

Poznanski RR, Umino O (1997) Syncytial integration by a network of coupled bipolar cells in the retina. Prog Neurobiol 53:273-291.

Ren JQ, Aika Y, Heizmann CW, Kosaka T (1992) Quantitative analysis of neurons and glial cells in the rat somatosensory cortex, with special reference to GABAergic neurons and parvalbumin-containing neurons. Exp Brain Res 92:1-14.

Sanchez MP, Frassoni C, Alvarez-Bolado G, Spreafico R, Fairen A (1992) Distribution of calbindin and parvalbumin in the developing somatosensory cortex and its primordium in the rat: an immunocytochemical study. J Neurocytol 21:717-736.

Sholl DA (1956) The organization of the cerebral cortex. London: Methuen.

Simons DJ, Carvell GE (1989) Thalamocortical response transformation in the rat vibrissa/barrel system. J Neurophysiol 61:311-330.

Sloper JJ (1972) Gap junctions between dendrites in the primate neocortex. Brain Res 44:641-646.

Sloper JJ, Powell TP (1978) Gap junctions between dendrites and somata of neurons in the primate sensori-motor cortex. Proc R Soc Lond B Biol Sci 203:39-47.

Stauffer D, Aharony A (1992) Introduction to percolation theory, Ed 2. London: Taylor and Francis.

Swadlow HA (1989) Efferent neurons and suspected interneurons in S-1 vibrissa cortex of the awake rabbit: receptive fields and axonal properties. J Neurophysiol 62:288-308.

Swadlow HA, Weyand TG (1987) Corticogeniculate neurons, corticotectal neurons, and suspected interneurons in visual cortex of awake rabbits: receptive-field properties, axonal properties, and effects of EEG arousal. J Neurophysiol 57:977-1001.

Szabadics J, Lorincz A, Tamás G (2001) $\beta$ and $\gamma$ frequency synchronization by dendritic GABAergic synapses and gap junctions in a network of cortical interneurons. J Neurosci 21:5824-5831.

Tamás G, Buhl EH, Lorincz A, Somogyi P (2000) Proximally targeted GABAergic synapses and gap junctions synchronize cortical interneurons. Nat Neurosci 3:366-371.

Traub RD, Schmitz D, Jefferys JGR, Draguhn A (1999) High-frequency population oscillations are predicted to occur in hippocampal pyramidal neuronal networks interconnected by axoaxonal gap junctions. Neuroscience 92:407-426.

Traub RD, Kopell N, Bibbig A, Buhl EH, LeBeau FE, Whittington MA (2001) Gap junctions between interneuron dendrites can enhance synchrony of gamma oscillations in distributed networks. J Neurosci 21:9478-9486.

White EL (1989) Cortical circuits: synaptic organization of the cerebral cortex: structure, function and theory. Boston: Birkhäuser.

Whittington MA, Traub RD, Jefferys JGR (1995) Synchronized oscillations in interneuron networks driven by metabotropic glutamate receptor activation. Nature 373:612-615. 